Case Report

\title{
P-Chloroaniline Poisoning Causing Methemoglobinemia: A Case Report and Review of the Literature
}

\author{
Anna Sarah Messmer, Christian Hans Nickel, and Dirk Bareiss \\ Department of Emergency Medicine, University Hospital Basel, Petersgraben 2, 4031 Basel, Switzerland \\ Correspondence should be addressed to Anna Sarah Messmer; annamessmer@web.de
}

Received 19 November 2014; Revised 23 January 2015; Accepted 1 February 2015

Academic Editor: Oludayo A. Sowande

Copyright ( 2015 Anna Sarah Messmer et al. This is an open access article distributed under the Creative Commons Attribution License, which permits unrestricted use, distribution, and reproduction in any medium, provided the original work is properly cited.

\begin{abstract}
Background. Methemoglobin (MetHb) most commonly results from exposure to an oxidizing chemical but may also arise from genetic, dietary, or even idiopathic etiologies. P-chloroaniline (PCA) was one of the first substances described in the context of acquired methemoglobinemia. Case Report. We report the case of a cyanotic chemistry worker who presented to our emergency department (ED) after working with PCA. His peripheral oxygen saturation $\left(\mathrm{SpO}_{2}\right)$ measured by pulse oximetry was at $81 \%$ and remained on that level despite oxygen administration (100\% oxygenation via nonrebreather mask). His MetHb level was measured at $42.8 \%$ in arterial blood gas analysis. After treatment with intravenous methylene blue cyanosis resolved and the patient was discharged after 36 hours of observation. Conclusion. Acquired methemoglobinemia is a treatable condition, which may cause significant morbidity and mortality. The knowledge about the most common causes, fast diagnostic, and proper treatment is crucial.
\end{abstract}

\section{Background}

Methemoglobinemia is a treatable condition that may cause significant morbidity and mortality [1]. Various systems normally operate to keep methemoglobin (MetHb) at physiologic level, which is less than $1 \%$ of the total hemoglobin concentration [2]. Methemoglobinemia is a result of the oxidation of ferrous iron $\left(\mathrm{Fe}^{2+}\right)$ to ferric iron $\left(\mathrm{Fe}^{3+}\right)$ within the hemoglobin molecule.

This becomes important in the context of oxygen transport and delivery: the ferric state is unable to bind oxygen, and the remaining ferrous (reduced) hemoglobin has a higher affinity for oxygen molecules (allosteric effect), shifting the oxygen-hemoglobin dissociation curve to the left. Consequently, the release of oxygen to the tissues is limited [1-4]. As an example, a patient with a hemoglobin level of $10 \mathrm{~g} / \mathrm{dL}$ who has $50 \%$ MetHb has only $5 \mathrm{~g} / \mathrm{dL}$ functional hemoglobin able to bind oxygen and deliver it to tissues.

Most commonly, methemoglobinemia is acquired and a result of ingestion or skin exposure to an oxidizing agent such as certain medications or chemicals; see Table $1[1,2$, $5,6]$. Aniline and its derivatives have been one of the first substances described to cause methemoglobinemia. Due to the awareness of its toxicity in industrial products, safety measures have been undertaken and acute aniline poisoning became rare in developed countries, reflected in case reports dated back to several decades $[7,8]$. However, our case report shows that accidental aniline or $p$-chloroaniline (PCA) poisoning can nowadays still induce significant, life-threatening methemoglobinemia.

\section{Case Report}

A 56-year-old patient with known epilepsy in his past medical history presented to the emergency department (ED) with generalized cyanosis four hours after cleaning a floor in a chemical factory. He was using PCA in solid form, which was dissolved with methanol. While working, he was using a facemask and a full body protection suit, which, according to his team leader, might have been defective. Later, a work colleague noticed that his skin color turned blue. According to the local occupational health guidelines, the patient immediately changed his clothes and took a shower to decontaminate.

In the ED, he was mildly confused and giddy, but he did not suffer from dyspnea. His vital signs showed mild 
TABLE 1: Substances that can cause MetHb ${ }^{1}$.

\begin{tabular}{|c|c|c|}
\hline \multicolumn{2}{|c|}{ Drugs } & \multirow{2}{*}{$\begin{array}{l}\text { Chemical agents } \\
\text { Acetanilide }\end{array}$} \\
\hline Acetaminophen & Methylene blue & \\
\hline Ammonium nitrate & Metoclopramide & Alloxan \\
\hline Amyl nitrate & Nitrates/nitrites & Aminophenol \\
\hline Anticonvulsants & Nitric oxide & Anilines \\
\hline Valproic acid & Nitrofurantoin & Automobile exhaust fumes \\
\hline Phenytoin & Nitroglycerine & Benzene \\
\hline Antimalaria drugs & Nitroprusside & Bivalent copper \\
\hline Chloroquine & Nitrous oxide & Burning wood and plastic \\
\hline Quinacrine & Isobutyl nitrate & Chlorates \\
\hline Primaquine & Oral hypoglycemics & Chromates \\
\hline Bismuth subnitrate & p-Aminosalicylic acid & Dimethyl sulfoxide \\
\hline Dapsone & Phenacetin & Dinitrophenol \\
\hline Flutamide & Phenazopyridine & Fumes \\
\hline Hydroxylamine & Piperazine & Naphthalene \\
\hline Local anesthetics & Rifampin & Nitrates \\
\hline Benzocaine & Riluzole & Nitrites \\
\hline Bupivacaine & Sulfadiazine & Nitrobenzene \\
\hline Lidocaine & & Nitroethane \\
\hline Prilocaine & & Nitrophenol \\
\hline \multirow[t]{4}{*}{ EMLA* $^{*}$} & & Paraquat \\
\hline & & Propanil \\
\hline & & Toluidine \\
\hline & & Trinitrotoluene (TNT) \\
\hline
\end{tabular}

This list is not complete. ${ }^{1}$ References: see $[6,21,25] .{ }^{*}$ Eutectic mixture of local anesthetics.

tachycardia with 107 beats per minute, blood pressure of $156 / 89 \mathrm{mmHg}$, and peripheral oxygen saturation $\left(\mathrm{SpO}_{2}\right)$ of $81 \%$ on a nonrebreather facemask (100\% oxygenation). Arterial blood drawn immediately was of dark brown color and the blood gas analysis revealed a $\mathrm{pH}$ of $7.401, \mathrm{pO}_{2}$ of $8.33 \mathrm{kpa}$ $(62.5 \mathrm{mmHg}), \mathrm{pCO}_{2}$ of $5.49 \mathrm{kpa}(41.2 \mathrm{mmHg})$, and an arterial oxygen saturation $\left(\mathrm{SaO}_{2}\right)$ of $93.4 \%$. The fraction MetHb measured in arterial blood by spectrophotometry was found to be elevated at $42.8 \%$, while the fraction of oxyhemoglobin $\left(\mathrm{O}_{2} \mathrm{Hb}\right)$ was $54.6 \%$, and the fraction of reduced hemoglobin ( $\mathrm{HHb}$ ) was $3.9 \%$ (see Table 2 ).

The patient was treated immediately with $150 \mathrm{mg}$ $(2 \mathrm{mg} / \mathrm{kg})$ intravenous methylene blue over 5 minutes. A sample of arterial blood gas obtained 30 minutes after treatment revealed a MetHb level of $12.3 \%$; therefore, another dose of $150 \mathrm{mg}$ of methylene blue was given. The patient's condition improved rapidly, the cyanosis resolved, and the patient was transferred to our intensive care unit for observation of possible rebound methemoglobinemia. Serial MetHb measurements showed a continued decrease to below $2 \%$. The patient was discharged 36 hours later.

\section{Discussion}

In 1959, aniline poisoning has been first described in a case series of marking-ink poisoning causing methemoglobinemia in babies [7]. Later, more cases have been published, most often in correlation with dye or herbicides exposure [9-12]. PCA is a colorless or slightly amber colored crystalline solid with a mild aromatic odor. The chemical is soluble in water and in common organic solvents, such as methanol used in our case. The general public may be exposed to PCA from the use of PCA-based dyed or printed textiles, papers, cosmetics, and pharmaceutical products. It can be dermal (wearing of clothes, use of soaps, or mouthwashes), oral (small children sucking clothes and other materials and use of mouthwashes), or direct entry into the bloodstream (e.g., through breakdown products of chlorhexidine in spray antiseptics) $[9,13]$. The mechanism of exposure in our case remains unclear. The team leader, who accompanied the patient to the ED, hypothesized a defective protection suit, whereas the PCA could have contaminated the skin.

Patients with methemoglobinemia typically present with skin discoloration ("chocolate cyanosis"), especially of the nails, lips, and ears, whereas the color is more often brown rather than blue. Even at low levels of MetHb, this discoloration can be striking [14].

The characteristic chocolate brown color of the blood is used as a simple bed side test to determine MetHb levels (visible at levels from 15\% upwards) to guide treatment in settings of limited resources [15].

Acute methemoglobinemia should be suspected in patients with central cyanosis with low peripheral oxygen saturation not responding to high flow oxygen therapy [16]. 
TABLE 2: Arterial blood gas before and after administration of first dose of methylene blue $150 \mathrm{mg}$.

\begin{tabular}{lcc}
\hline & $\begin{array}{c}\text { Before } \\
\text { methylene blue }\end{array}$ & $\begin{array}{c}\text { After } \\
\text { methylene blue }\end{array}$ \\
\hline $\begin{array}{l}\mathrm{FiO}_{2} \text { (fraction of inspired } \\
\text { oxygen) }\end{array}$ & $21 \%$ & $100 \%$ \\
$\mathrm{pH}$ & 7.401 & 7.378 \\
$\mathrm{pCO}_{2}[\mathrm{kPa}]$ & 5.59 & 5.01 \\
$\mathrm{pO}_{2}[\mathrm{kPa}]$ & 8.33 & 49.6 \\
$\mathrm{SaO}_{2}[\%]$ & 93.4 & 100 \\
$\mathrm{HCO}_{3}[\mathrm{mmol} / \mathrm{L}]$ & 25.5 & 22.1 \\
$\mathrm{Oximetry} \mathrm{results}^{\mathrm{Hb}(\text { hemoglobin [g/L]) }}$ & 130 & 108 \\
$\quad \mathrm{FO}$ Hb (fractional & 54.6 & 90.2 \\
oxyglobin [\%]) & & \\
$\quad \begin{array}{l}\mathrm{FCOHb} \text { (fractional } \\
\text { carboxyhemoglobin [\%]) }\end{array}$ & 0 & 0 \\
$\quad \begin{array}{l}\text { FMetHb (fractional } \\
\text { MetHb [\%]) }\end{array}$ & 42.8 & 12.3 \\
Lactate [mmol/L] & 0.7 & 0.4 \\
\hline
\end{tabular}

Arterial whole blood was analyzed on an ABL90 series blood gas analyzer, Radiometer Medical, Denmark. Arterial blood gas analyzers are based on electrochemistry and measure $\mathrm{pH}, \mathrm{pCO}_{2}$, and $\mathrm{pO}_{2}$. Serum bicarbonate $\left(\mathrm{HCO}_{3}\right)$ and oxygen saturation $\left(\mathrm{SaO}_{2}\right)$ are calculated values (using the Henderson-Hasselbalch equation for serum bicarbonate and the standard oxygen-hemoglobin saturation curve for oxygen saturation).

The reason is that pulse oximetry may be inaccurate for monitoring oxygen saturation in the presence of methemoglobinemia since conventional pulse oximeters measure ultraviolet absorption at only two wavelengths (940 and $660 \mathrm{~nm}$ ) to differentiate oxyhemoglobin from deoxyhemoglobin. To determine the oxygen saturation, the oximeter calculates the ratio of absorbance at the 2 wavelengths. A ratio of absorbance $(660 \mathrm{~nm} / 940 \mathrm{~nm})$ of 0.43 corresponds to $100 \%$, whereas a ratio of 1.0 corresponds to a saturation of $85 \%$. MetHb absorbs light equally at both 940 and $660 \mathrm{~nm}$. In the presence of $100 \% \mathrm{MetHb}$ the ratio of absorbance of light at $660 \mathrm{~nm}$ over $940 \mathrm{~nm}$ is about 1.0. Therefore, at higher MetHb levels, $\mathrm{SaO}_{2}$ tends toward $85 \%$ regardless of the true percentage of oxyhemoglobin $[2,17]$. In our case, the peripheral oxygen saturation was $81 \%$.

Another interesting phenomenon is demonstrated in our case report: the oxygen saturation shown in the arterial blood gas analysis $\left(\mathrm{SaO}_{2}\right)$ may be falsely elevated in patients with methemoglobinemia. The value is calculated based on the patients' $\mathrm{pO}_{2}$. The latter refers to dissolved gas and not to oxygen molecules bound to hemoglobin. Subjects with $\mathrm{MHb}$ may have normal $\mathrm{pO}_{2}$ levels despite life-threatening $\mathrm{MHb}$ [2].

Additionally, if an oxygen saturation gap $>5 \%$ exists between the calculated arterial saturation $\left(\mathrm{SaO}_{2}\right)$ in the blood gas analysis and the reading from the pulse oximeter $\left(\mathrm{SpO}_{2}\right)$ abnormal hemoglobin (e.g., methemoglobinemia) should be suspected $[1,18]$. In our case, the gap was $12.4 \%$.

Regardless of etiology, the severity of symptoms depends on the MetHb levels, reported as a percentage of total hemoglobin. Cyanosis caused by MetHb becomes clinically apparent at a MetHb level of about $15 \%$ of total hemoglobin. At levels between 30 and 50\%, as observed in our patient, dyspnea, headache, weakness and fatigue, dizziness, and sometimes syncope are described. Levels above $70 \%$ may cause death $[2,14]$. Anemia, acidosis, respiratory compromise, and cardiac disease may make patients more symptomatic than expected for a given MetHb level.

The most effective and widely used antidotal therapy is methylene blue, which was first described in 1933 in aniline dye poisoning $[19,20]$.

Treatment should be guided by the severity of the disorder and blood levels of MetHb represent a secondary parameter in the definition of the treatment. However, several authors suggest that methylene blue should be considered with MetHb above 30\%, regardless of the presence of symptoms $[14,20,21]$. Symptomatic patients or patients with preexisting conditions that interfere with tissue oxygenation should be treated at levels between $10 \%$ and 30\%. Standard dose of the intravenous administration is 1 to $2 \mathrm{mg} / \mathrm{kg}$ given as a $1 \%$ solution over 5 minutes [4]. In our case, the MetHb concentration after $30 \mathrm{~min}$ was still elevated at $12.3 \%$, and the patient seemed to still be clinically unwell. We were concerned about the patient's state and the fact that he may develop a possible rebound methemoglobinemia. Therefore, we have applied a second dose of methylene blue.

Notably, "desaturation" on the pulse oximeter after methylene blue administration, as seen in our patient, has been well documented and is known to be a result of interference by methylene blue on light absorbance [22]. This interference complicates the assessment of the patient's ability to oxygenate properly and may lead to administration of repeated doses of methylene blue. The patient's clinical status will provide the most useful information about their ability to oxygenate. According to the literature, a repeated dose may be necessary in severe cases of MetHb levels over $60 \%$ or if the patient's condition does not improve [20]. The maximal dose should not exceed $7 \mathrm{mg} / \mathrm{kg}$, since methylene blue at high doses may also precipitate MetHb formation [14, 20].

Methylene blue should be used with caution in individuals with severe renal insufficiency and in young patients with G6PD deficiency. This group of patients can develop hemolytic anemia characterized by formation of Heinz bodies without any reduction in MetHb levels [14, 20, 23]. Alternative therapies include exchange transfusion, hyperbaric oxygen, and ascorbic acid [24].

Excretion of PCA in humans occurs primarily via the urine, with PCA and its conjugates appearing as early as 30 min after exposure. Excretion takes place mainly during the first $24 \mathrm{~h}$ and is almost complete within $72 \mathrm{~h}$. Nephrotoxic and hepatotoxic potential of PCA has only been described in animal studies [13].

\section{Conclusion}

Our case shows a rare cause of methemoglobinemia. However, methemoglobinemia can be a complication of commonly used or prescribed medication in the $\mathrm{ED}$, that is, 
nitroglycerin, local anesthetics such as lidocaine, or metoclopramide. Methemoglobinemia should be suspected in a patient presenting with cyanosis not responsive to oxygen administration. The administration of methylene blue should be considered as antidotal therapy for MetHb concentrations over $30 \%$.

\section{List of Abbreviations}

MetHb: Methemoglobin

PCA: $\quad$-Chloroaniline

ED: Emergency department

$\mathrm{SpO}_{2}$ : Peripheral oxygen saturation

$\mathrm{SaO}_{2}$ : Arterial oxygen saturation

$\mathrm{pO}_{2}$ : Partial pressure of oxygen

$\mathrm{pCO}_{2}$ : Partial pressure of carbon dioxide.

\section{Consent}

Written informed consent was obtained from the patient for publication of this case report and any accompanying images. A copy of the written consent is available for review.

\section{Conflict of Interests}

The authors have declared that no competing interests exist.

\section{References}

[1] R. Ash-Bernal, R. Wise, and S. M. Wright, "Acquired methemoglobinemia: a retrospective series of 138 cases at 2 teaching hospitals," Medicine, vol. 83, no. 5, pp. 265-273, 2004.

[2] R. O. Wright, W. J. Lewander, and A. D. Woolf, "Methemoglobinemia: etiology, pharmacology, and clinical management," Annals of Emergency Medicine, vol. 34, no. 5, pp. 646656, 1999.

[3] S. M. Bradberry, "Occupational methaemoglobinaemia. Mechanisms of production, features, diagnosis and management including the use of methylene blue," Toxicological Reviews, vol. 22, no. 1, pp. 13-27, 2003.

[4] L. S. Nelson, N. A. Lewin, M. A. Howland, R. S. Hoffman, and L. R. Goldfrank, Goldfrank's Toxicoloic Emergencies, McGraw-Hill, New York, NY, USA, 2011.

[5] J. B. Sullivan and G. R. Krieger, "Clinical hematotoxicology," in Clinical Environmental Health and Toxic Exposures, chapter 28, Lippincott Williams \& Wilkins, Philadelphia, Pa, USA, 2nd edition, 2001.

[6] D. M. Roberts, R. Heilmair, N. A. Buckley et al., "Clinical outcomes and kinetics of propanil following acute self-poisoning: a prospective case series," BMC Clinical Pharmacology, vol. 9, article 3, 2009.

[7] D. E. Ramsay and C. Harvey, "Marking-ink poisoning: an outbreak of methemoglobin cyanosis in newborn babies," The Lancet, vol. 273, no. 7079, pp. 910-912, 1959.

[8] B. S. Kulkarni, V. N. Acharya, R. M. Khanna, S. Nath, R. P. Mankodi, and P. Raghavan, "Methemoglobinemia due to nitroaniline intoxication. Review of the literature with a report of 9 cases.," Journal of Postgraduate Medicine, vol. 15, no. 4, pp. 192200, 1969.
[9] A. F. Pizon, A. R. Schwartz, L. M. Shum et al., "Toxicology laboratory analysis and human exposure to p-chloroaniline," Clinical Toxicology, vol. 47, no. 2, pp. 132-136, 2009.

[10] A. Bazylewicz, T. Kłopotowski, M. Kicka, Ł. Miśkiewicz, and S. Picheta, "Acute poisoning due to chemical substances inducing methemoglobinemia-two cases report," Przeglas lekarski, vol. 67, no. 8, pp. 636-639, 2010.

[11] B. E. Watt, A. T. Proudfoot, S. M. Bradberry, and J. A. Vale, "Poisoning due to urea herbicides," Toxicological Reviews, vol. 24, no. 3, pp. 161-166, 2005.

[12] R. Thier, J. Lewalter, S. Selinski, and H. M. Bolt, "Biological monitoring in workers in a nitrobenzene reduction plant: haemoglobin versus serum albumin adducts," International Archives of Occupational and Environmental Health, vol. 74, no. 7, pp. 483-488, 2001.

[13] A. K. J. Boehncke, G. Könnecker, C. Poehlenz-Michel et al., "Concise International Chemical Assessment," Document 48: 4-Chloroaniline 2003.

[14] K. R. Olsen, "Poisoning and drug overdose," in Methylene Blue by Fabian Garza, pp. 902-904, McGraw-Hill, New York, NY, USA, 5th edition, 2007.

[15] F. Shihana, D. M. Dissanayake, N. A. Buckley, and A. H. Dawson, "A simple quantitative bedside test to determine methemoglobin," Annals of Emergency Medicine, vol. 55, no. 2, pp. 184189,2010

[16] S. BheemReddy, F. Messineo, and D. Roychoudhury, "Methemoglobinemia following transesophageal echocardiography: a case report and review," Echocardiography, vol. 23, no. 4, pp. 319-321, 2006.

[17] S. J. Barker, K. K. Tremper, and J. Hyatt, "Effects of methemoglobinemia on pulse oximetry and mixed venous oximetry," Anesthesiology, vol. 70, no. 1, pp. 112-117, 1989.

[18] J. Akhtar, B. D. Johnston, and E. P. Krenzelok, "Mind the gap," The Journal of Emergency Medicine, vol. 33, no. 2, pp. 131-132, 2007.

[19] C. F. Williams, "Methylene blue as an antidote for aniline dye poisoning," Journal of Laboratory and Clinical Medicine, vol. 1, pp. 166-171, 1933.

[20] J. Clifton II and J. B. Leikin, "Methylene blue," The American Journal of Therapeutics, vol. 10, no. 4, pp. 289-291, 2003.

[21] T. S. do Nascimento, R. O. L. Pereira, H. L. D. de Mello, and J. Costa, "Methemoglobinemia: from diagnosis to treatment," Revista Brasileira de Anestesiologia, vol. 58, no. 6, pp. 651-664, 2008.

[22] M. R. Kessler, T. Eide, B. Humayun, and P. J. Poppers, "Spurious pulse oximeter desaturation with methylene blue injection," Anesthesiology, vol. 65, no. 4, pp. 435-436, 1986.

[23] P. Sikka, V. K. Bindra, S. Kapoor, V. Jain, and K. K. Saxena, "Blue cures blue but be cautious," Journal of Pharmacy and Bioallied Sciences, vol. 3, no. 4, pp. 543-545, 2011.

[24] P. Boran, G. Tokuc, and Z. Yegin, "Methemoglobinemia due to application of prilocaine during circumcision and the effect of ascorbic acid," Journal of Pediatric Urology, vol. 4, no. 6, pp. 475476, 2008.

[25] R. B. Abu-Laban, P. J. Zed, R. A. Purssell, and K. G. Evans, "Severe methemoglobinemia from topical anesthetic spray: case report, discussion and qualitative systematic review," Canadian Journal of Emergency Medicine, vol. 3, no. 1, pp. 51-56, 2001. 


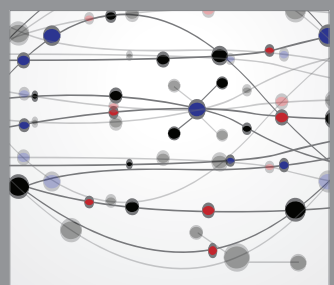

The Scientific World Journal
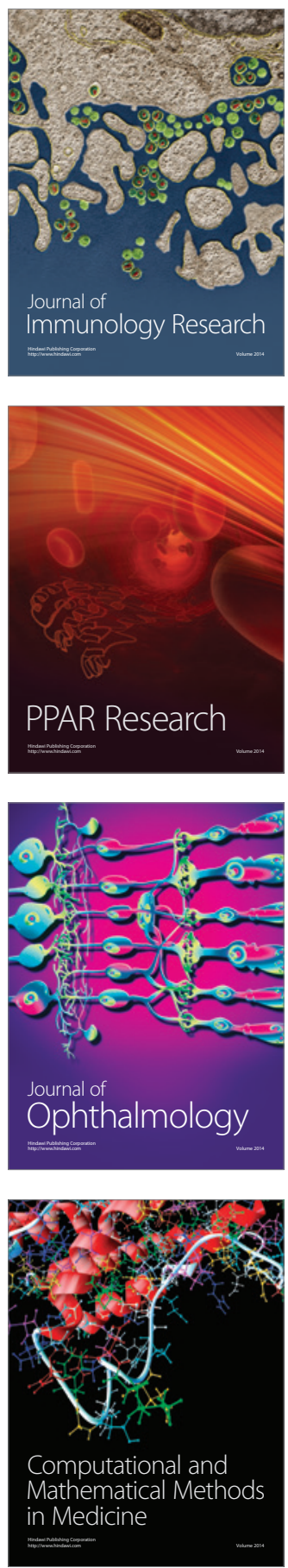

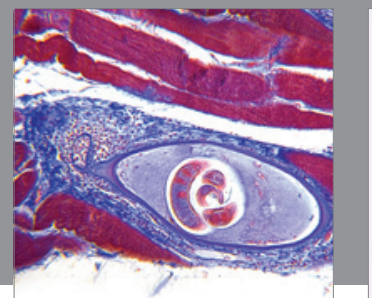

Gastroenterology

Research and Practice
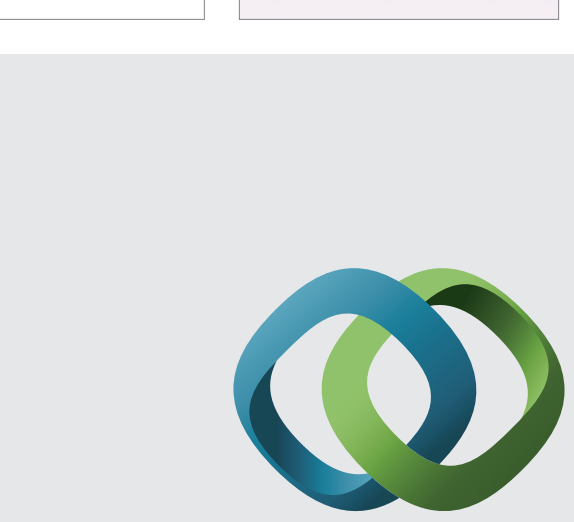

\section{Hindawi}

Submit your manuscripts at

http://www.hindawi.com
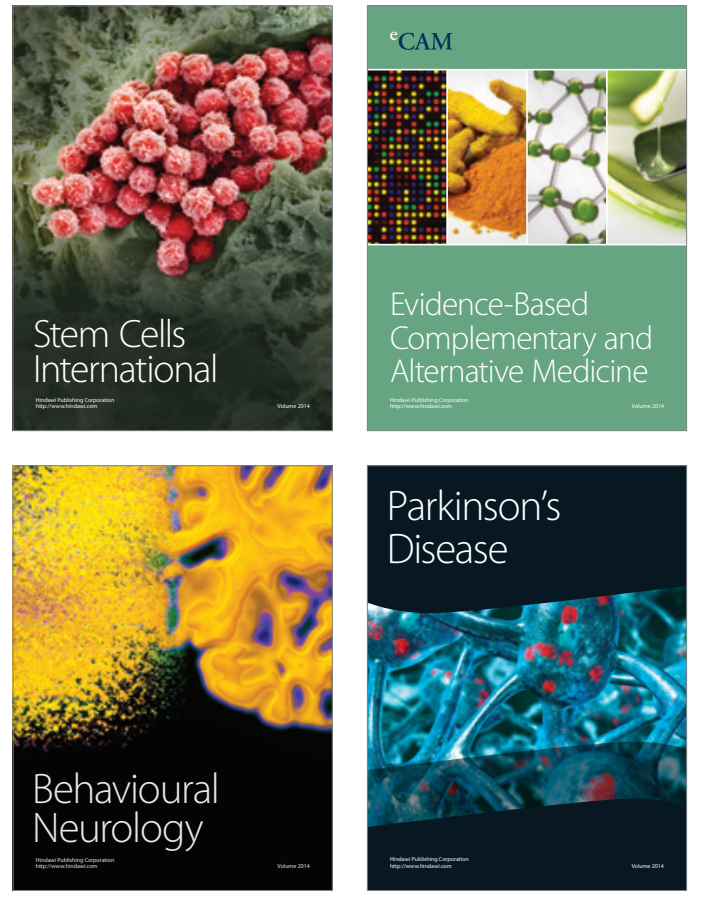
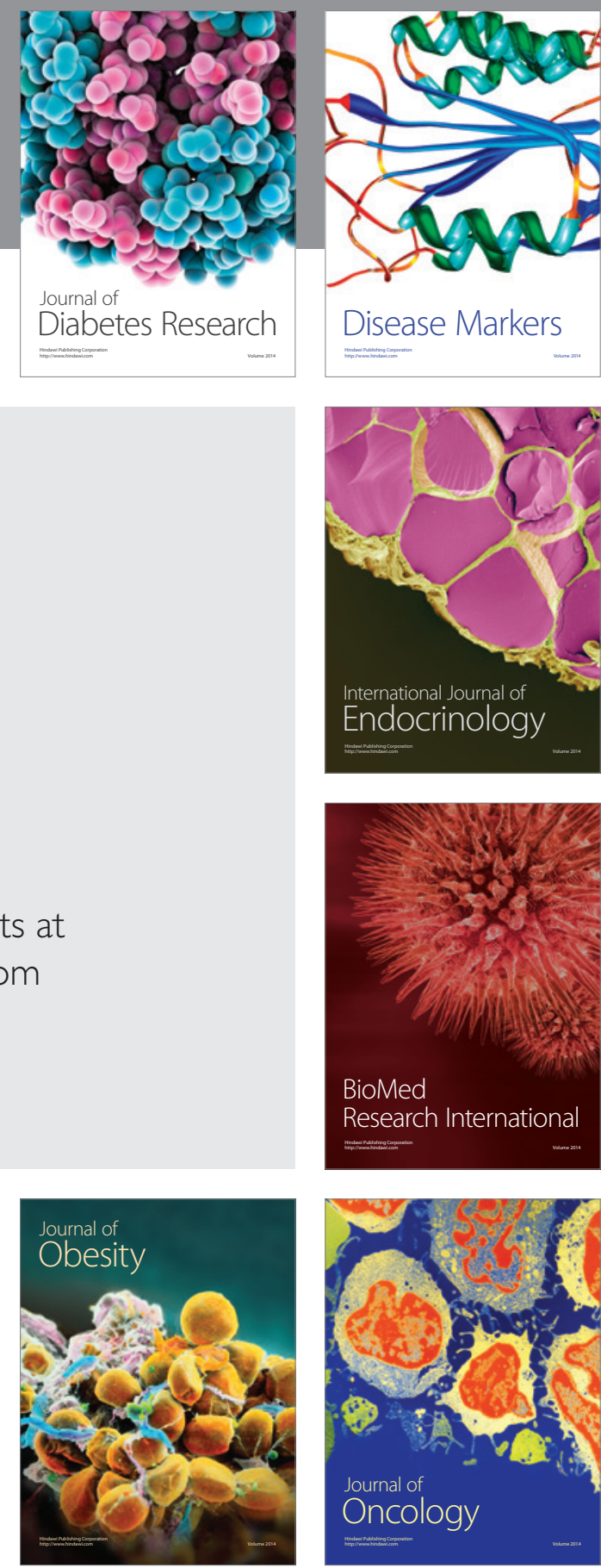

Disease Markers
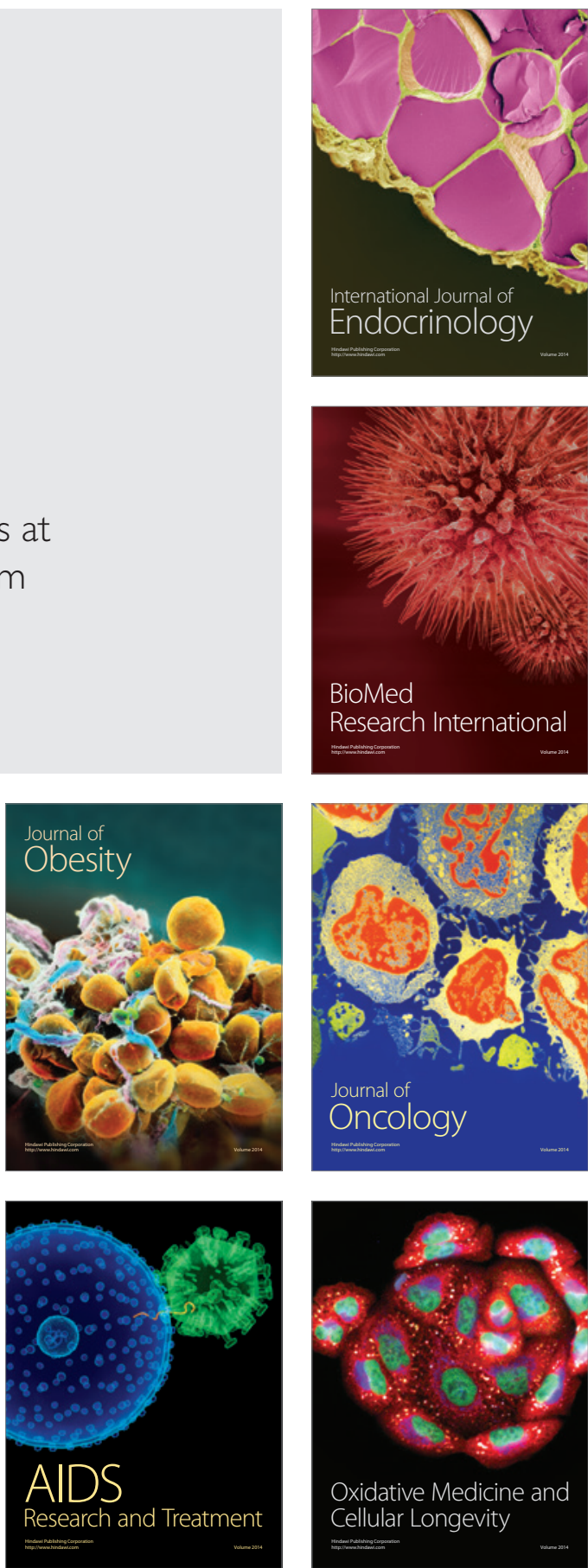